\title{
LA ETNOHISTORIA EN LA UNIVERSIDAD DE BUENOS AIRES: UN RECORRIDO POR 30 AÑOS DE INVESTIGACIONES
}

\author{
ETNOHISTORY IN BUENOS AIRES UNIVERSITY: \\ A WALK THROUGH 30 YEARS OF INVESTIGATIONS
}

\author{
Carlos Zanolli*, Alejandra Ramos ${ }^{* *}$, Dolores Estruch ${ }^{* *}$, Julia Costilla $^{* *}$
}

\begin{abstract}
En este trabajo ahondaremos en el desarrollo de la etnohistoria en el espacio particular de la sección homónima perteneciente al Instituto de Ciencias Antropológicas de la Facultad de Filosofía y Letras de la Universidad de Buenos Aires. Analizaremos la producción de esta Sección como una variante más de todas las etnohistorias que, nosotros afirmamos, existen en la actualidad y que se han ido desarrollando según las dinámicas propias de los equipos de investigación de cada país en donde el campo disciplinar se desarrolló a partir de los años ochenta.
\end{abstract}

Palabras claves: Etnohistoria, Universidad de Buenos Aires, historia disciplinar.

In this work we will dig into the development of Ethnohistory in the curricular space of the homonym Section from the Anthropological Institute of the Faculty of Philosophy and Letters of Buenos Aires University. We will analyze the production of this Section as a particular version of all the ethnohistories that, according to us, actually exist and that have been growing with the dynamic of their investigation teams on the countries where Ethnohistory has developed since the 1980s.

Key words: Ethnohistory, Buenos Aires University, disciplinary history.

\section{Introducción}

En este trabajo ahondaremos en el desarrollo de la etnohistoria en el espacio particular de la sección homónima perteneciente al Instituto de Ciencias Antropológicas de la Facultad de Filosofía y Letras de la Universidad de Buenos Aires. Presentamos la producción de la Sección no de manera aséptica, sino como una variante más de todas las etnohistorias que, nosotros afirmamos, existen en la actualidad y que se han ido desarrollando según las dinámicas propias de los equipos de investigación de cada país en donde el campo disciplinar se desarrolló a partir de los años ochenta.

El análisis propuesto tendrá presente tres aspectos: a) las dinámicas institucionales y el lugar geográfico desde donde se ha realizado la producción etnohistórica, b) los sentidos que ha adquirido la dimensión temporal de la etnohistoria y cómo ha sido repensada la relación entre pasado y presente y c) los desafíos del diálogo interdisciplinario y las problemáticas de orden teórico-metodológico acerca de la construcción de objeto/preguntas para una investigación en etnohistoria.

En el primer caso, partiremos de la creación de la Sección Etnohistoria ligada al Instituto y al Departamento de Ciencias Antropológicas de la UBA, por ende, con una institucionalización estrechamente vinculada a la antropología antes que a otras disciplinas. En lo que hace al punto b), es decir, la relación entre pasado y presente, debemos señalar que durante la década de 1880 , al momento de la consolidación del Estado-Nación, comenzaron a escribirse parte de las "Historias de la Nación Argentina", las que contribuyeron a la creación de una historia nacional que a partir de innumerables repeticiones se mantuvo en el sentido común de la gente hasta bien pasada la segunda mitad del siglo XX (Mitre 1950 [1887]). En ellas el indígena jugaba un rol de cierta preponderancia pero solo en aquellos lugares donde había quedado marginado. Desde esos lugares, los indígenas habían resistido los embates conquistadores del imperio incaico primero y posteriormente colaborado en

\footnotetext{
* Universidad de Buenos Aires, Facultad de Filosofía y Letras, Sección Etnohistoria. Instituto Nacional de Antropología y Pensamiento Latinoamericano, Buenos Aires, Argentina. Correo electrónico: cezanolli@ hotmail.com

** Universidad de Buenos Aires, Facultad de Filosofía y Letras, Sección Etnohistoria. Buenos Aires, Argentina. Correos electrónicos: alejandraramos_@hotmail.com; doloestruch@yahoo.com.ar; juliacostilla@ hotmail.com
} 
las luchas independentistas. Así las cosas, el inca comenzará a incorporarse a la historia nacional recién a finales de la década de 1960 a partir de las propuestas de ciertos arqueólogos. La producción de la Sección Etnohistoria se inició dentro de ese marco contextualizando históricamente al indígena y contribuyendo a la visibilización actual del mismo. Por fin, en cuanto al diálogo interdisciplinario, en un primer momento y de manera estratégica, la Sección estrechó lazos con representantes locales tanto del campo de la arqueología como de la historia. Esta apuesta, como veremos, permitió armar proyectos amplios que posibilitaron, en cada una de las disciplinas, la formación de tesistas y becarios y la consecuente ampliación de los equipos. Con el tiempo, y ya con parte de aquellos formados, los representantes de las distintas disciplinas seguirían su desarrollo específico.

Siguiendo estos aspectos, para desarrollar nuestro objetivo nos detendremos a continuación en dos apartados. En el primero realizaremos una breve reseña de las características de la producción etnohistórica en las últimas cuatro décadas. Luego, enmarcados en ese panorama, analizaremos con mayor profundidad el proceso de institucionalización de la Sección Etnohistoria de la UBA.

\section{La etnohistoria andina: un recorrido posible}

Antes de comenzar este "recorrido posible", quisiéramos enfatizar que la nuestra no es más que una de las tantas miradas que se pueden hacer del proceso de conformación de este campo disciplinar. Para realizarlo tomaremos ciertos hitos característicos: el balance que realizara John Murra en 1970, los Congresos internacionales de etnohistoria y algunas compilaciones que en aquellos momentos señalaban caminos y líneas de investigación. Entendemos también que estos hitos, si bien están determinados por una fecha fija, reflejan procesos a veces de cinco, a veces de más años en los cuales el campo disciplinar en estudio desarrolla pausadamente aquellos perfiles propios que luego serán reseñados en eventos, compilaciones y balances.

Las investigaciones desarrolladas en Perú durante las décadas de 1960 y 1970 por John Murra, John Rowe, María Rostworoski, Luis Valcárcel y Tom Zuidema, entre otros, contemplaron la triple conjunción de los aportes de la historia, la arqueología y la antropología. Como la imaginaban sus promotores, la etnohistoria vendría a dar nombre al esfuerzo conjunto de distintos acercamientos que en el pasado se habían ejercido por separado (Murra 1975). Luego sobrevino toda una generación de investigadores (Nathan Wachtel, Franklin Pease, Steve Stern, Pierre Duviols, Ana María Lorandi, Tristan Platt, Frank Salomón, Olivia Harris, Thérèse Bouysse-Cassagne, Jorge Hidalgo y Thierry Saignes, entre tantos otros), cuyas obras se han constituido en los principales referentes para la etnohistoria andina más allá de la propia autodefinición disciplinar de cada autor. Tales producciones se fueron articulando con los trabajos de investigadores locales en distintos centros académicos de América Latina (Ecuador, Bolivia, Perú, Chile y Argentina, entre otros) en un proceso que involucraba, al menos en los primeros tiempos y dentro de distintas posiciones teóricas, temáticas compartidas y objetivos comunes. De manera que fueron confluyendo hacia la etnohistoria investigadores que, aunque de distinta formación y en algunos casos hasta con orientaciones teórico-metodológicas opuestas, tenían como común denominador el interés por el mundo andino y el rescate de su historia cultural a partir de la búsqueda y el estudio de las más variadas fuentes literarias y documentales de los siglos XVI y XVII, analizadas a la luz de las modernas perspectivas y categorías antropológicas y cotejadas, ahí donde fuera posible, con relatos etnográficos e informes arqueológicos en una perspectiva de larga duración (Curátola 2002: 58-59).

En 1970, Murra realizó una evaluación de los cambios producidos en las investigaciones respecto de las dos décadas previas, los mismos se resumían en cuatro avances significativos: 1) la publicación de fuentes clásicas, lo que facilitaba su acceso y conducía a un incremento en las investigaciones; 2) el aumento de los estudios acerca de los antecedentes, la personalidad y el contexto intelectual de los autores de los documentos; 3 ) el surgimiento de nuevas preguntas para estudiar las fuentes disponibles evidenciándose una tendencia a incorporar textos literarios como fuentes; 4) la incorporación, en esta misma línea, de documentos administrativos, entre los que se destacaron las visitas. Estos dos últimos puntos fueron acompañados por una perspectiva novedosa vinculada al interés por los asentamientos locales y los estudios comparativos (Murra 1975).

Si el balance de 1970 de Murra da cuenta de los rasgos de la etnohistoria, inmediatamente después surgieron una pluralidad de temas generales, aunque con efectos inclusivos, como por ejemplo el 
tópico de la desestructuración que se instala tras la publicación La visión de los vencidos de Wachtel. El trascender límites nacionales a partir de temas de interés comunes dio lugar, ya desde la década de 1970 pero sobre todo a partir de los años ochenta, a un intenso diálogo entre los investigadores de distintos países y disciplinas. En este sentido, la realización en 1970 del Congreso de Americanistas en Perú contribuyó notablemente a que las temáticas andinas incrementaran su relieve internacional. Otros encuentros que aportaron a tal fin fueron el Seminario comparativo de Andes y Mesoamérica de 1972, el Proyecto de investigación de reinos lacustres (Arica, La Paz, Puno) y el Congreso del Hombre Andino, ambos en 1973, y el otoño andino organizado en 1976 en la Universidad de Cornell.

La década de 1980 estuvo marcada por la pluralidad de investigaciones surgidas tras la expansión regional de la etnohistoria andina y los debates respecto de cómo definir este campo. Con diferentes ritmos, los estudios etnohistóricos fueron incorporados en Ecuador, Bolivia, Chile, Colombia y Argentina, enriqueciéndose con los aportes realizados desde cada uno de estos países (Ramos et al. 2010-2011; Zanolli et al. 2010). En un contexto de proliferación de encuentros y de incremento notable de la producción de artículos individuales y colectivos, se destacaron tres compilaciones que tuvieron su origen en la reunión convocada en 1981 por el Joint Committee on Latin American Studies perteneciente al Social Science Research Council (SSRC) y el American Council of Learned Societies (ACLS) con el objetivo de "diseñar un proyecto sobre la historia andina" (Stern 1990: 19). En ella estuvieron presentes Brooke Larson, Steve Stern, Carlos Sempat Assadourian, José María Caballero, Magnus Mörner, John Murra, Silvia Rivera, Karen Spalding y Enrique Tándeter y se esbozó la posibilidad de realizar tres conferencias interrelacionadas entre sí, "que pretendían desarrollar nuevas hipótesis y conclusiones basadas en los recientes avances de la historia y la etnología andinas y plantear orientaciones para investigaciones futuras" (Stern 1990: 19). La primera reunión tuvo lugar en 1983 bajo el nombre de "Penetración y expansión del mercado en los Andes, siglos XVIXX" y fue coordinada por Olivia Harris, Brooke Larson y Enrique Tándeter; la segunda titulada "Reproducción y transformación de las sociedades andinas, siglos XVI-XX" estuvo a cargo de Frank Salomon y Segundo Moreno en 1986; ese mismo año Steve Stern organizó "Resistencia, rebelión y conciencia campesina en los Andes, siglos XVIII al XX". Cada una de las reuniones daría lugar luego a una compilación.

Con estos y otros encuentros nacionales y regionales como antecedentes, a fines de los años ochenta se crearon los Congresos internacionales de etnohistoria (CIE), cuya continuidad se mantiene hasta el presente, aunque con una significativa interrupción entre 1998 y 2005. Estos congresos, sobre todo en su primera etapa, donde primaban los intereses comunes y marcos compartidos -grandes modelos explicativos para la organización política y económica de las sociedades andinas-, se constituyeron en uno de los principales espacios de intercambio. Ya entrado el siglo XXI se hicieron sentir con más fuerza los desarrollos particulares de los países anfitriones y la creciente especialización al interior de la etnohistoria andina.

De manera que, entendiendo las fechas como hitos dentro de procesos amplios, pensamos que -luego de la sistematización de Murra en 1970¹-en el devenir de la etnohistoria pueden identificarse al menos dos grandes etapas: una primera que se ve plasmada en el I CIE realizado en Buenos Aires en 1989 y en los inmediatamente posteriores; y una segunda que comenzará con los primeros años del nuevo siglo tras un hiato entre los encuentros: los siete años que pasaron hasta el próximo congreso (Buenos Aires 2005) indudablemente señalaban que algo estaba sucediendo.

El CIE de 1989 se presenta como la primera gran instancia de encuentro de dos conjuntos de investigadores, aquellos pioneros que con Perú como centro habían sido los principales impulsores de la disciplina y otros que motivados por el primer grupo avanzaban en estudios propios de áreas localizadas generalmente dentro de los límites territoriales de los países de pertenencia. No obstante los casos de estudios particulares, había varios intereses y marcos de referencias compartidos (foco en lo étnico, control vertical, reciprocidad, redistribución, ayllu, cacicazgos, mitimaes, forasteros, etc.). En otras palabras, lo que parecía ser un "estudio propio" no era más que un diálogo regional, ya que como un rompecabezas parecía imposible avanzar en los estudios de uno sin entender los estudios del otro.

Así, tanto en el primer Congreso de Buenos Aires como en los de Coroico y El Quisco, se plasma un momento de la disciplina en el que, podríamos decir, hay acuerdo respecto de los términos del diálogo. 
Luego se harán notar los saltos generacionales, el incremento de investigadores y las diversificaciones temáticas propias de los desarrollos particulares de los cada vez más numerosos equipos de investigación locales. En los dos últimos congresos de esta primera etapa (Lima 1996 y Jujuy 1998) se pusieron de manifiesto nuevos procesos al interior de la disciplina, que si bien habían comenzando a gestarse en la década del noventa, recién se terminarían plasmando durante la segunda etapa a partir del CIE de 2005 realizado en Buenos Aires.

Los siete años que separaron al CIE de Jujuy respecto del de Buenos Aires, ambos en Argentina, estaban dando cuenta de ciertos cambios que se habían producido tanto a nivel de las ciencias en general, de la disciplina en particular y también de los actores que la llevaban adelante. Tras la primera expansión de las investigaciones y la consecuente apertura de nuevos espacios académicos no se hicieron esperar discusiones en torno al lugar de la etnohistoria dentro de las ciencias sociales. Los debates acerca de la definición de la etnohistoria se desarrollaron a partir de tres ejes: el método y la importancia de la comparación, generalmente reconocida pero no siempre llevada a la práctica; el objeto - ¿quiénes son los sujetos de la etnohistoria? si son los grupos étnicos, ¿esa categoría solo se aplica a nativos? ¿Podemos hacer etnohistoria de españoles y criollos?-; y la disciplina, es decir, si se trata de un campo autónomo o si se encuentra subsumida a otra disciplina y, si es así, ¿a la antropología o a la historia? (Lorandi y Wilde 2000; Santamaría 1985; Viazzo 2003). La dificultad de darle una respuesta acabada a estos debates debe ser considerada teniendo en cuenta que estos se produjeron en un contexto en que la idea misma de definir a las disciplinas por un objeto y un método específico estaba siendo cuestionada.

En las ciencias sociales en general, al tiempo que los límites entre disciplinas se volvían cada vez más difusos, se empezaba a escribir respecto de la caída de los grandes relatos y el fin de la historia. Estas ideas cobraron fuerza tras la caída del Muro de Berlín y la disolución de la URSS y a grandes rasgos tuvieron dos consecuencias principales para el desenvolvimiento de la ciencias sociales en general y de la etnohistoria en particular: por un lado al primar una visión de fragmentación y pluralidades, los grandes modelos explicativos fueron perdiendo la fuerza que los había caracterizado. Por el otro, se inauguró una nueva etapa en las investigaciones a partir de la oleada de reemergencias étnicas: en este sentido, Lauer (en Lanata 2005) propone pensar comparativamente los reclamos de autonomía y acceso a la estatalidad de los movimientos indígenas y los procesos políticos similares que acompañaron el desmembramiento de la URSS.

En lo estrictamente académico, ya en la década de 1990 surgió una notable presión para avanzar en títulos de posgrado. Algo como el doctorado, que años atrás formaba parte de la "culminación" de la vida académica, ahora era una instancia fundamental para avanzar en la misma. Este hecho hizo que una importante cantidad de investigadores debieran dedicar gran parte de su tiempo de trabajo a finalizar los posgrados antes que a diseñar grandes congresos disciplinares. De hecho, casi todo el equipo que luego organizó en Buenos Aires el CIE de 2005, se doctoró entre el 2000 y el 2004.

De todas formas, el distanciamiento entre Congresos tenía otros condimentos. A su interior, los equipos de etnohistoria de los distintos países se habían ampliado explorando y en muchos casos ampliando temas y geografías no tradicionales. Respecto de lo geográfico, el Chaco, las Tierras Bajas y el Amazonas iban cobrando protagonismo dentro del tradicional mundo andino; en lo temático: memoria, género, siglo XIX, criollos, hispanos y afrodescendientes. De hecho, los nuevos temas no siempre estuvieron ligados a aquellos otros que habían enmarcado el primer ciclo de Congresos, ampliando y diversificando los caminos iniciales que caracterizaron a la etnohistoria. Esta ampliación temática y geográfica respondía no solo al crecimiento de investigadores sino también a la mayor cantidad de material documental descubierto y sobre todo a su mayor accesibilidad a partir de las nuevas tecnologías.

Tal vez un buen ejemplo de estos casos haya sido el propio CIE de 2005, el que dio cuenta -como veremos más adelante- de los cambios ocurridos en la Sección en la última década, ampliando los rangos históricos y los temas propios de la etnohistoria. En el caso de Lima (2008) se invitaba a realizar una reflexión y discusión pertinente a semejanzas y diferencias entre países, regiones, territorios y procesos, tomando en cuenta las particularidades culturales e interculturales de cada uno de ellos. La idea de una América comparada puede ser pensada como parte de la apuesta a una América andina, que en términos políticos comenzaba a proponerse como eje de integración sudamericana (Lumbreras 1999). 
En Sucre (2011) el subtítulo de "Etnohistoria más allá de las etnias" ponía en evidencia la particular coyuntura política que vivía el país en aquel momento.

El último encuentro en Arica introdujo una notoria modificación en la organización del Congreso, lanzando una convocatoria abierta a los investigadores para las propuestas de mesas cuando usualmente la comisión organizadora anunciaba el llamado a ponencias para mesas ya preestablecidas. Esta modalidad por un lado tuvo la ventaja de abrir la propuesta temática y contemplar la diversidad de aspectos en los que los investigadores del área se encuentran trabajando, más allá de la inclinación propia de los estudios en el país anfitrión. Pero por otro lado, la amplia variedad de mesas hizo difícil asistir a todos los encuentros que uno quisiera. Esta imposibilidad de acceso no fue exclusiva de este Congreso y de esta nueva modalidad de mesas: ya en Sucre - que tuvo una menor cantidad-no resultaba sencillo seguir las presentaciones. Claramente, esto obedece también al incremento de investigadores que presentan sus trabajos en los CIE y a la dinámica de organización que han ido adquiriendo en el transcurso de los años.

Llegados a este punto actual, volveremos a continuación acerca de este recorrido posible que trazamos para historizar la etnohistoria andina, dispuestos a analizar en ese marco el desarrollo de la Sección Etnohistoria de la UBA.

\section{La institucionalización de la etnohistoria en Argentina}

En el ámbito de la Universidad de Buenos Aires (UBA) la etnohistoria encontró un espacio de institucionalización a principios de los años ochenta con la creación de la Sección homónima. La misma se dio en el marco de la reorganización del ICA, cuya dirección había sido encargada por las autoridades de la Facultad de Filosofía y Letras a la doctora Ana María Lorandi².

Desde sus orígenes, el espacio institucional de la Sección se encontró influenciado por los desarrollos contemporáneos de la etnohistoria andina y principalmente por los trabajos de Murra, con quien la directora del equipo había mantenido un frecuente contacto desde su primer encuentro en 1967, en la región de Huánuco, Perú. Respecto de ese permanente intercambio teórico y empírico con los especialistas de la región andina, en menos de una década la Sección fue logrando una plena consolidación, evidenciado esto en una sucesión ininterrumpida de proyectos aprobados, en su capacidad organizativa para convocar eventos internacionales y en la significativa formación de recursos humanos. Fue en ese marco que puedo realizarse en 1989 el primer CIE en Buenos Aires, nutrido en parte gracias al fluido contacto entre investigadores de los Andes centrales y meridionales.

Considerando este hito, seguiremos el objetivo de este apartado tomando una primera etapa de consolidación, que abarca desde la creación de la sección en 1985 hasta mediados de los años noventa, y un segundo momento de crecimiento y diversificación del equipo que llega hasta la actualidad. Abordaremos sus lazos de filiación con la etnohistoria andina como su propia especificidad en gran medida asociada al importante rol jugado por la antropología en su desarrollo. En este sentido, advertiremos que si bien las primeras investigaciones impulsadas desde la Sección combinaron los aportes de la antropología, la historia y la arqueología, la imposibilidad de extrapolación total del marco interpretativo andino demandó un abordaje particular desde la teoría antropológica (Boixadós 2000). Asimismo, demostraremos que su inserción institucional dentro del espacio académico de la antropología, como el perfil de sus integrantes -en su mayoría provenientes de esta disciplina-, ha tenido un peso fundamental en el desarrollo de sus investigaciones.

\section{Primera etapa: creación y consolidación}

El surgimiento de la Sección Etnohistoria en el año 1985 se dio bajo la influencia de una nueva forma de estudiar las sociedades andinas debida en gran medida a la tarea de investigación y difusión que realizó Murra. El profundo cambio que implicó su manera de abordar a las sociedades indígenas, impulsando una forma de trabajo que combinaba el aporte de múltiples disciplinas, se combinó con su perfil de "predicador" (Ávila Molero 2000; Lorandi y del Río 1992; Ramos 2010). Murra supo desarrollar un intenso intercambio con investigadores y estudiantes, presentando sus libros y modelos a lo largo de Latinoamérica (Lorandi 2006). Fue justamente por medio de este investigador que la doctora Lorandi se familiarizó con la nueva corriente.

Dentro de ese contexto de expansión regional de la etnohistoria tuvo lugar la creación de la Sección en la Facultad de Filosofía y Letras de la UBA. 
Aquí, el desarrollo de los estudios etnohistóricos y su institucionalización se vieron propiciados por la combinación de dos factores principales: una coyuntura política y académica adecuada y la propia trayectoria profesional y personal de Lorandi. La coyuntura estuvo dada por el restablecimiento de la democracia luego de varios años de dictadura militar (1976-1983) que afectaron notablemente la institucionalidad de la UBA y, particularmente, la de la Licenciatura en Ciencias Antropológicas ${ }^{3}$.

Pero la coyuntura no era solamente política. Años antes la teoría arqueológica había experimentado importantes cambios especialmente de la mano de Alberto Rex González, quien, a partir de sus propias excavaciones y de la seriación de colecciones previas, "estableció en el país la primera sucesión cronológica cultural confiable" (Matera et al. 2009: 14-15) e introdujo la datación por radiocarbono. La doctora Lorandi fue parte activa en estos dos procesos, el de cambio de paradigma en la arqueología nacional y el de expansión e institucionalización de la etnohistoria en Argentina.

A lo largo de esos primeros años la Sección se consolidó como un espacio académico. Allí se desarrolló la formación de un equipo de investigación interdisciplinario con numerosos proyectos, tesistas y becarios de la UBA y del Consejo Nacional de Investigaciones Científicas y Técnicas (CONICET), instituciones que también otorgaron subsidios para financiar las investigaciones y el equipamiento.

A partir de lo que fue una apuesta teórica común tomada por varios países de la región, los estudios que comenzaron a desarrollarse en la UBA se particularizaron por centrar su objeto de estudio geográficamente en el sur andino: noroeste argentino y sur de Bolivia. Se entendía en aquel entonces que el Tucumán colonial correspondía a un área periférica del imperio incaico, con sociedades con un mayor grado de segmentación respecto de las de los Andes centrales. Orientados hacia el análisis de las comunidades indígenas de esa área, los trabajos iniciales de la Sección intentaron reconstruir el mapa étnico de la región y abordaron temas como la encomienda, la tributación y la mano de obra, los procesos de resistencia y rebeliones, la movilidad social y el problema de las tierras.

De esa manera, Lorandi y su equipo lograron apropiarse de los aportes de la etnohistoria (tal como había sido concebida en los países pioneros) situándola en la perspectiva local e inaugurando una nueva forma de pensar el lugar de las sociedades indígenas de la región tanto dentro del imperio incaico como dentro de la sociedad colonial. Tal vez una de las consecuencias más importantes de lo ocurrido en aquellos años fue la reelaboración del modelo de la etnohistoria nacido para el estudio de los Andes centrales. Mientras la etnohistoria andina fue conformando una producción teórica propia, el estudio de las zonas periféricas puso en evidencia la necesidad de recurrir a un abordaje desde la teoría antropológica mucho más amplio y diverso. Ya en los primeros trabajos Lorandi había advertido la dificultad de una traspolación directa de los marcos de interpretación andinos debido a las particularidades del Tucumán: su colonización tardía, el proceso de resistencia y rebeliones indígenas, la ausencia de riquezas fácilmente explotables, su difícil integración debido a las grandes distancias que lo separaban de los principales centros de poder y su localización geopolítica son algunos de los aspectos que lo singularizan. Esta especificidad del área, y la de su documentación disponible, requirió otras opciones de interpretación adecuadas a problemáticas puntuales y recurrir a producciones antropológicas más tradicionales (Boixadós 2000).

Pero tal apropiación particular de la producción referida al contexto andino no implicó abandonar la inserción local en un contexto mayor que vinculaba investigaciones etnohistóricas de distintas regiones. Así, se trató de una primera generación de trabajos que vincularon a la sección con el mundo andino y su problemática colonial, pero que al mismo tiempo dieron y fijaron identidad a las producciones de este espacio académico (cfr. Lorandi 1997).

El balance de los cambios y acontecimientos ocurridos en la Sección entre 1988 y 1993 es altamente positivo: a poco de cumplir diez años de vida, se fue consolidando como un espacio académico institucional dentro del universo de la antropología de la UBA. Cimentó su presencia dentro del ICA, fruto de los numerosos proyectos radicados en una sección dependiente del mismo, y dentro de la Licenciatura en Ciencias Antropológicas, a partir de la propuesta de la materia Sistemas Socioculturales de América II, al poco tiempo de crearse el equipo, y de un Seminario Anual de Investigación. La consecuencia fue un crecimiento cuantitativo de tesistas y becarios, además de un continuo acercamiento de estudiantes interesados en explorar sus temáticas propias. La realización del primer CIE le brindó un plano de visibilidad internacional, para ello también contribuyó la publicación de Memoria Americana, 
revista que desde 1991 brindó un espacio para difundir la producción de la sección y la de muchos investigadores extranjeros. Al sostenido crecimiento que se dio a partir de 1985 le siguió entonces una etapa de consolidación, la que, como es de esperar, produjo cuestionamientos y cambios.

\section{Segunda etapa: hacia la diversificación del equipo}

En el marco de la etnohistoria andina, como vimos, la década de 1990 implicó una renovación y ampliación de los trabajos, alejándose estos de lo que había sido el "paraguas" del control vertical. Esto fue generando trayectorias particulares, uno de cuyos casos fue el de la etnohistoria en Argentina: allí, el ámbito de la UBA fue escenario de varios cambios paulatinos en las investigaciones etnohistóricas que condujeron a una diversificación del objeto de estudio.

En primer lugar, el Tucumán colonial fue quedando como un espacio que dejaba de ser simplemente marginal del área andina: el noroeste argentino ya no se pensaba solamente en términos de extremo del imperio incaico y se establecieron estudios regionales a partir de otros "cortes" posibles del territorio. Al mismo tiempo, a partir de las características propias del tipo de documentación con el que se contaba y en función de la propia historia nacional -especialmente respecto de las áreas geográficas atravesadas por las campañas de expansión de la frontera a fines del siglo XIX-se observó un movimiento hacia temporalidades más recientes y hacia una ampliación geográfica. En buena medida como una respuesta al agotamiento de las fuentes disponibles para el Noroeste argentino en relación con las temáticas que se venían trabajando ${ }^{4}$ y paralelamente a una búsqueda de nueva documentación dentro de los repositorios ya explorados), fueron sumándose a la tradicional área andina meridional las regiones de Pampa y Patagonia -que si bien ya se venían trabajando se incorporan a la sección- y luego el Gran Chaco y Paraguay. De esta manera fueron integrándose investigadores que si bien se identificaban como etnohistoriadores no lo hacían como etnohistoriadores andinos. Asimismo, sin que la línea de trabajos vinculados al estudio de las comunidades indígenas quedara totalmente interrumpida, un importante número de miembros de la sección fue dirigiendo sus intereses hacia la sociedad hispano-criolla, considerando sus actores individuales e instituciones y los procesos de interacción entre minorías y elites, enfatizando la idea de contacto.

De manera que, si bien su institucionalización estuvo atravesada por el modelo panandino de control vertical, la etnohistoria argentina fue transformándose en relación con las regiones de estudio, temporalidades y temáticas señaladas. Correrse de los tradicionales siglos XVI y XVII, abordar nuevos actores y explorar nuevos espacios geográficos llevó a que muchas de estas líneas de investigación quedaran en parte desprovistas de marco teórico con el cual analizar, pensar y plantear sus problemáticas de investigación: si el que ofrecía la etnohistoria andina no era suficiente o del todo indicado para ello ¿cómo se expresaron esas transformaciones y cuáles fueron los desarrollos teóricos que las acompañaron?

Una de las primeras diferencias sustanciales que expresan los proyectos de investigación radicados en la Sección durante la década del noventa ${ }^{5}$ es la inclusión del bloque relacionado con la sociedad hispano-criolla. Los objetivos se orientarían no solo al "análisis de los cambios sociodemográficos en la sociedad nativa", sino a "profundizar y ampliar los estudios etnohistóricos desde la perspectiva de la sociedad hispano-criolla", analizando "las prácticas, las redes de poder y las construcciones del imaginario entre los conquistadores y los nuevos actores que la dinámica social fue haciendo emerger". Esta apertura quedaba justificada, en la formulación de los proyectos, por el número considerable de miembros que integraban el equipo ${ }^{6} \mathrm{y}$ porque la gran mayoría de ellos había comenzado a analizar "la larga duración y la posibilidad de una aproximación al presente".

La ampliación temático-temporal, unida a la inclusión de nuevos becarios, terminó de concretarse en un segundo proyecto -PIP CONICET 1997-1999 (4141) - a partir de la incorporación de dos nuevos temas de investigación: uno acerca de "representaciones simbólicas y el ejercicio del poder" y otro que buscó combinar el trabajo de archivo con el trabajo de campo; ambos, mantenidos hasta la actualidad como temas propios de la sección. Respecto de la presencia hispano-criolla, dejó de ser planteada como un objetivo separado para señalarse que "las transformaciones del mapa étnico y las categorías sociales y la reestructuración de las relaciones de fuerza en el campo político y social" proponen ser analizadas en una continuidad desde el siglo XVI 
hasta el siglo XIX. Mientras los temas ya establecidos se profundizan, algunos ganan mayor especificidad y otros se diversifican, tomándose los aportes de los estudios urbanos y campesinos, junto a los de género, familia e iglesia. Asimismo, continúa el corrimiento temporal que busca dejar una brecha cada vez menor entre las investigaciones respecto del pasado y aquellas vinculadas al presente.

Debido a estos cambios que las nuevas investigaciones pusieron en marcha, la sección fue movilizando una consecuente renovación teórica y metodológica. Materializada en seminarios internos y en reflexiones publicadas en un número especial de la revista Memoria Americana (año 2000), dicha renovación implicaba una actualización de enfoques pero conservando el espíritu comparativo de la antropología. Al modelo de análisis preexistente fueron incorporándose las nuevas líneas desarrolladas en el seno de la historia social francesa, así como las propuestas de la microhistoria italiana, los aportes de autores como Anthony Giddens y Pierre Bourdieu -cuyas obras incidieron en las ciencias sociales en general-y las influyentes contribuciones de antropólogos como Marshall Sahlins y Jean y John Comaroff. Fue apareciendo entonces la referencia a la antropología histórica como marco teórico para la investigación, que permitiría combinar, por una parte, el análisis de la estructura social con el de los acontecimientos $y$, por otra, los enfoques en escalas micro y macro. La antropología histórica era entendida como el estudio de "las representaciones simbólicas y en las prácticas significativas de vida cotidiana [...] la búsqueda del sentido que una sociedad o grupo otorga a sus acciones y representaciones"

De esta manera, los replanteos teórico-metodológicos se vieron acompañados de un pasaje terminológico, de etnohistoria a antropología histórica, que puede entenderse como un verdadero "salto cualitativo" (Zanolli y Rodríguez 2004: 91). El abandono del término etnohistoria se habría dado, por una parte, por el deseo de separarse de una palabra que limitaba el desarrollo de las nuevas temáticas y, por otra, en un intento de acercamiento a la antropología, ya que las actividades académicas de los miembros de la sección (asistencia a congresos, evaluaciones, publicaciones, etc.) se encontraban más vinculadas con la historia. La etnohistoria, desde la perspectiva de algunos investigadores de este equipo, podía vincularse a una "influencia norteamericana de los cincuenta, de los estudios orientados a lo precolombino, al primer momento de contacto con el español" mientras que la antropología histórica era ligada a "otra tradición académica", concretamente a la línea francesa, y resultaba más amplia como área disciplinar ${ }^{8}$.

En suma, hacia fines del siglo XX la antropología histórica irrumpió en la Sección como sinónimo pero a la vez diferenciándose de la etnohistoria, en una década en la que este espacio institucional, ya plenamente consolidado y con proyección internacional, comenzaba a transitar una nueva etapa. Impulsada en parte por cierto agotamiento de las fuentes para el área tradicionalmente estudiada, fue produciéndose una apertura tanto de los temas y problemas a abordar como de los marcos geográficos y temporales. Todos estos cambios en la definición del objeto de estudio estuvieron, como es lógico, íntimamente ligados a una actualización teórico-metodológica, fruto de nuevas formas de pensar que se estaban dando tanto en la historia como en la antropología y en las ciencias sociales en general; y esta actualización de enfoques, a su vez, posibilitó el surgimiento de nuevas preguntas y problemáticas de trabajo. De esta manera, en un juego en donde teoría, metodología y objeto de estudio se influyen mutuamente en una relación dialéctica, el viraje nominal hacia la antropología histórica fue el corolario de un proceso de recambio en el que se puso en revisión tanto el objeto como la forma de abordarlo. No parece casual, por tanto, que con la consolidación de estos cambios la denominación de antropología histórica haya llegado prácticamente a disputar un lugar en la propia designación de la producción surgida en la sección.

\section{Consideraciones finales}

Tal vez este trabajo exceda la idea de presentar el desarrollo de la etnohistoria en la UBA; tal vez conlleve más la intención de pensar cómo se han ido desarrollando las distintas etnohistorias según la consolidación de los equipos de investigación locales. Es cierto también que no podríamos haber hecho esto último sin considerar lo que para nosotros fue el desarrollo de la etnohistoria desde la década de 1970 y a base de esa idea contextualizar lo ocurrido dentro de la Sección Etnohistoria de la UBA, en definitiva la que más conocemos y de la que somos partícipes.

Con la etnohistoria pasó lo que pasa con todas las cosas: cambió; y esos cambios se fueron 
registrando a lo largo del tiempo en hechos como las compilaciones, los estados de la cuestión, el formato interno que fueron adquiriendo los congresos internacionales de la disciplina, las formas de comunicación de los investigadores, etc. No ligar esos cambios a ciertos factores externos sería sin dudas un error. De la misma manera que avanzaba la década de 1980 el mundo, su política y su economía también comenzaba a cambiar. En lo político, y luego de la caída del Muro de Berlín, comenzaba a anunciarse el "fin de la Historia", señalando las bases de una nueva democracia liberal (Fukuyama 1992). En lo económico, lentamente se iba consolidando el paso de un capitalismo industrial a otro financiero; en definitiva la propia modernidad se alejaba cada vez más de las bases que hace siglos le habían dado sustento. Es impensable que estos cambios globales no afectaran a las ciencias sociales. Además de la caída de los grandes modelos explicativos, en lo estrictamente académico cambiaron las instancias de legitimación cobrando notable trascendencia los posgrados. En lo que hace a los países de Latinoamérica que nos ocupan (Perú, Chile, Bolivia, Argentina, Brasil, Uruguay, etc.) observamos que muchos de ellos comenzaban a vivir los períodos democráticos prácticamente más largos de su historia, aquellas democracias traían también significativas asignaciones presupuestarias para los distintos sectores de la educación y la investigación. Es en estas consideraciones generales que se insertan los equipos de investigación locales, los que además quedan ligados a sus propias vicisitudes.

$\mathrm{El}$ interjuego entre los cambios en la disciplina y los cambios en los equipos de investigación es más que claro. La ampliación de personas trajo necesariamente la ampliación temática y la de las áreas de estudio. Los grandes temas que antes unían $y$ en alguna medida unificaban a los etnohistoriadores de los distintos países fueron perdiendo su peso específico. Es en ese contexto cuando tal vez comenzó a escribirse este trabajo. En Argentina, como explicamos en el último apartado, el agotamiento de las fuentes tempranas para los estudios "étnicos" del Tucumán colonial fue abriendo las puertas a nuevos actores sociales, que si bien habían sido considerados en las investigaciones anteriores no estaban en el centro de la escena; y por lógica consecuencia la apertura temática nos colocó en siglos más tardíos. Así, la idea de una Sección de Etnohistoria dejó de dar cuenta, semánticamente, de las investigaciones que se venían realizando. Primero como sinónimo de etnohistoria y luego diferenciándose de ella, el término antropología histórica expresó un proceso paralelo que se dio en la Sección durante la década de 1990: un sólido acercamiento a la antropología en detrimento de la historia. Se abrían paso temas tales como la justicia, las identidades provinciales, una historia comparada de la religión y los desarrollos de la disciplina, entre tantos otros, ello se verificó en la convocatoria del CIE de 2005.

Creemos que este proceso no es propio ni exclusivo de Argentina y particularmente de la Sección Etnohistoria de la que venimos hablando. Los desarrollos de los Congresos que le siguieron al de Buenos Aires nos permiten suponer que las cuestiones que venimos tratando para nuestro caso podrían verificarse, con sus particularidades, para otros equipos locales. Trabajar en ellas excede el marco del presente artículo, pero seguramente hacerlo dimensionaría el campo disciplinar que nos cobija hace ya varios años.

\section{Agradecimientos}

A nuestros colegas de la Sección Etnohistoria, a los organizadores del IX Congreso Internacional de Etnohistoria y a los evaluadores anónimos de este manuscrito.

\section{Referencias Citadas}

Ávila Molero, J.

2000 Entre archivos y trabajo de campo: la etnohistoria en el Perú. En No hay país más diverso. Compendio de Antropología Peruana, editado por C. I. Degregori, pp. 180203. IEP- PUCP -Universidad del Pacífico, Lima.

Boixadós, R.

2000 ¿Etnohistoria de La Rioja? Proyecciones y límites de una práctica interdisciplinaria. Memoria Americana 9: 131156. FFyL, UBA, Buenos Aires.
Curatola, M.

2002 El pasado andino como profesión y como vocación: la (etno) historia de Franklin Pease G.Y. En El Hombre y los Andes. Homenaje a Franklin Pease G.Y., editado por J. Flores Espinoza y R. Varín Gabai, pp. 49-74. PUCP, Lima. Matera, S., M. Kergaravat, M. Di Donatto y F. Weber 2009 Una reseña sobre arqueología argentina. En Charlas, un Encuentro con la Arqueología Argentina. Imago Mundi, Buenos Aires. 
Michieli, T.

2010 Desarrollo de los trabajos sobre etnohistoria de Cuyo e historia de la población indígena de San Juan en la época colonial en el Instituto de Investigaciones Arqueológicas y Museo "Prof. Mariano Gambier" (UNSJ). Ponencia presentada en Jornadas " $25^{\circ}$ de Etnohistoria en Argentina", Buenos Aires.

Mitre, B.

1950 [1887] Historia de San Martín y de la Emancipación Sudamericana. Editorial Tor, Buenos Aires.

Murra, J.

1975 Las investigaciones en etnohistoria andina y sus posibilidades en el futuro. En Formaciones Económicas y Políticas del Mundo Andino. IEP, Perú.

Fukuyama, F.

1992. The End of History and the Last Man. Planeta, Madrid.

Lanata, X. (comp.).

2005. Actas del debate. En Vigencia de lo Andino en los Albores del siglo XXI. Una mirada desde el Perú y Bolivia. CBC, Cusco.

Lorandi, A.M.

1997 El Tucumán Colonial y Charcas. Buenos Aires, UBA, FFyL.

2006 Homenaje al maestro John Murra: 1916-2006. Memoria Americana 14: 205-210. FFyL, UBA, Buenos Aires.

Lorandi, A.M. y M. del Río

1992 La etnohistoria. Etnogénesis y Transformaciones Sociales Andinas. Centro Editor de América Latina, Buenos Aires.
Lorandi, A.M. y G. Wilde

2000 Desafío a la isocronía del péndulo. Acerca de la teoría y de la práctica de la antropología histórica. Memoria Americana 9: 37-78.

Lumbreras, L.

1999 Historia de América Andina. Vol. 1: Las Sociedades Aborígenes. Libresa, Quito.

Ramos, A.

2010 La Etnohistoria Andina antes de su Consolidación. Confluencias Disciplinares y Propuestas TeóricoMetodológicas. Colección Tesis de Licenciatura. Sociedad Argentina de Antropología, Buenos Aires.

Ramos, A., C. Zanolli, D. Estruch y J. Costilla

2010-2011 Etnohistoria andina: antecedentes y consolidación. Novedades de Antropología 20 (66): 3-6.

Stern, S. (comp.).

1990 Resistencia, Rebelión y Conciencia Campesina en los Andes. Siglos XVIII al XX. IEP, Lima.

Viazzo, P.

2003 Introducción a la Antropología Histórica. Fondo Editorial de la PUCP/Instituto Italiano de Cultura, Lima.

Zanolli, C. y L. Rodríguez

2004 La antropología histórica: entre la tradición académica y las prácticas de investigación. Revista Historia Indígena 8: 89-100.

Zanolli, C., D. Estruch, A. Ramos y J. Costilla

2010 Historia, Representaciones y Prácticas de la Etnohistoria. Una Aproximación Antropológica a un Campo de Confluencia Disciplinar. Antropofagia, Buenos Aires.

\section{Notas}

1 Esto no quiere decir que desconozcamos el periodo anterior, de hecho lo hemos abordado en Zanolli et al. (2010), sin embargo para los fines de esta presentación hemos decidido concentrarnos en los sucesos posteriores a la década de 1970.

2 Si bien la Sección Etnohistoria se destaca debido a la continuidad temporal y al crecimiento de sus miembros, entre los espacios de institucionalización de este campo en Argentina -y por eso nos centramos en ella- es necesario destacar que ya sea trabajando individualmente o en equipo varios arqueólogos, historiadores y antropólogos se acercaron a las propuestas de la etnohistoria. En general no lo hicieron identificándose a sí mismos como etnohistoriadores, sino recuperando alguna de sus herramientas o señalando los beneficios de incorporar este enfoque en sus investigaciones. Tras su inserción inicial en la Sección Etnohistoria Ana María Presta conformó su propio equipo dentro de los espacios institucionales de la carrera de historia y del Instituto Ravignani -que actualmente dirige- de la Facultad de Filosofía y Letras (UBA). Si pensamos en Jujuy surgen los nombres de Daniel Santamaría, Gabriela Sica, Sandra Sánchez y Ana Teruel; Salta nos remite a Guillermo Madrazo y Sara Mata; Cristina López y Estela Noli se constituyen en referentes para Tucumán. Mientras que Marcela Tamagnini, Josefina Piana y Silvia Palomeque lo son en el caso de Córdoba. Ejemplo de esto son también los trabajos de Nidia Areces (Rosario), Teresa Michieli (San Juan) y Raúl Mandrini (Buenos Aires), entre otros (Nacuzzi y Lorandi 2007). En este sentido también se han realizado proyectos y eventos que podemos tomar como indicios de la consolidación de la etnohistoria en Argentina. Uno de estos lo constituyen las Jornadas de Etnohistoria Sudamericana realizadas en 1984, para ellas se convocaron representantes del sur de Brasil, el centro y el norte de Chile y el Litoral, Cuyo, las Sierras Centrales y la Patagonia de Argentina. Previas a los Congresos Internacionales de Etnohistoria, la importancia de estas Jornadas no solo radica en su temprana temporalidad sino, y principalmente, porque modificaba "la tradicional dirección longitudinal de temática andina e introducía un nuevo sentido, transversal, desde el Atlántico al Pacífico" (Michieli 2010). De cierta manera esta tendencia fue continuada por las Jornadas de Investigadores en Arqueología y Etnohistoria del Centro-Oeste del País, que se realizaron por primera vez en 1993, en Río Cuarto. Estas Jornadas fueron impulsadas por el Laboratorio de Arqueología y Etnohistoria (Departamento de Historia, Facultad de Ciencias Humanas, Universidad Nacional de Río Cuarto) que desde 1987 desarrolla investigaciones de la Frontera Sur. Además, en las jornadas realizadas en 2001 surgió el interés por conformar "un grupo dedicado a discutir problemáticas, aspectos teóricos y metodológicos ligados a la Etnohistoria, vinculando todos los territorios que ha comprendido históricamente la Frontera Sur" (www.unrc.edu.ar/ publicar/tefros). El ya mentado Laboratorio convocó a una reunión en 2002 y allí se estableció el Taller de Etnohistoria de la Frontera Sur (TEFROS), actualmente coordinado por Marcela Tamagnini.

3 La carrera reabría sus puertas luego de haber sido cerrada durante la dictadura.

4 A excepción de las que se llevaban adelante para la jurisdicción de San Salvador de Jujuy. En relación con este aspecto nos resulta de sumo interés lo desarrollado por Boixadós (2000: 137) 
respecto de las posibilidades y límites que brindan las fuentes disponibles para el Tucumán Colonial.

5 Se trata de proyectos dirigidos por Ana María Lorandi y financiados tanto por UBA como por CONICET. Nos referiremos puntualmente al UBACyT FI 090 (1994-1997), "Cambio y continuidad en la sociedad indígena e hispanocriolla, siglos XV-XIX".

6 Ya desde fines de 1993, la Sección Etnohistoria contaba con aproximadamente veinte integrantes, considerando becarios, investigadores formados, adscritos a la cátedra y personal de apoyo técnico.

PIP CONICET 1997-1999 (4141).

8 Retomamos aquí las palabras de una de las entrevistadas que formaron parte de la investigación que fue plasmada en Zanolli et al. (2010). Con el objetivo de mantener el anonimato de los entrevistados se les asignó una letra acompañada de su formación de grado y pertenencia institucional, en este caso la cita corresponde a: Entrevistada N, antropóloga, UBA. 
